\title{
LOS MATERIALES DIDÁCTICOS PARA LA ENSEÑANZA DE LA HISTORIA EN LA FORMACIÓN DOCENTE
}

\author{
Victor Amado Salto ${ }^{1}$ \\ Alicia Graciela Funes ${ }^{2}$
}

\begin{abstract}
Resumen: La elaboración de materiales didácticos para la enseñanza de la historia requiere de fundamentos teóricos y prácticos sobre: para que educar y enseñar historia, donde y cuando hacerlo, con quienes entablar diálogos críticos y creativos a partir de proyectos educativos. Problematizar la construcción del conocimiento histórico y de su enseñanza invita a explorar el cambio que ofrece múltiples escenarios educativos. Pensar para elaborar materiales de la enseñanza junto con el profesorado es centrar la intencionalidad en el mundo del sujeto- estudiantado y profesorado- y en las finalidades en tanto compromiso político-social, además de científico. Por ello, el eje central de este artículo estará constituido por el análisis de prácticas de investigación y formación que profesoras y profesores desarrollan en el campo de la enseñanza del conocimiento histórico.
\end{abstract}

Palabras-clave: Materiales didácticos. Finalidades. Formación docente.

\section{MATERIAIS DIDÁTICOS PARA O ENSINO DA HISTÓRIA NA FORMAÇÃO DE PROFESSORES}

Resumo: O desenvolvimento de materiais didáticos para o ensino da história requer fundamentos teóricos e práticos sobre: para educar e ensinar história, onde e quando fazê-lo, com quem se envolver em diálogos críticos e criativos baseados em projetos educacionais. A problemização da construção do conhecimento histórico e seu ensino convida a explorar a mudança oferecida por múltiplos cenários educacionais. Pensar desenvolver materiais do ensino junto com os professores é focar a intencionalidade no mundo do assunto- estudo e professores - e nos propósitos do compromisso político-social, bem como científico. Portanto, o foco central deste artigo será a análise das práticas de pesquisa e treinamento que os professores desenvolvem no campo do ensino do conhecimento historico.

Palavras-chave: Materiais didáticos. Finalidades. Formação de professores

\section{DIDACTIC MATERIAL FOR TEACHING HISTORY IN TEACHER'S EDUCATION}

\begin{abstract}
The development of teaching materials for teaching history requires theoretical and practical foundations about: educate and use history, where and when to do it, with whom it is

\footnotetext{
${ }^{1}$ Profesor en Historia y Especialista en Didáctica de las Ciencias Sociales. Ha indagado sobre líneas de investigación vinculadas a: la enseñanza de la (nueva) Historia política en el nivel medio y en la formación del profesorado en Historia, en la enseñanza y el aprendizaje de la Historia reciente, y de las ciencias sociales y la Historia en contextos de cultura digital. Es Profesor formador en las cátedras de Didáctica General y Especial de la Historia y de Práctica Docente en el profesorado en Historia (Facultad de Humanidades/Universidad Nacional del Comahue). Profesor formador en la cátedra de Didáctica de las Ciencias Sociales en el profesorado en enseñanza primaria (Facultad de Ciencias de la Educación/Universidad Nacional del Comahue). Actualmente ejerce como investigador de la Facultad de Ciencias de la Educación en la Universidad Nacional del Comahue (Argentina).

${ }^{2}$ Profesora en Historia, Especialista, Magister en Didáctica y Doctora en Ciencias de la Educación, se desempeña como Profesora Titular Regular de la Universidad Nacional del Comahue. Argentina. Directora de Proyectos de Investigación, Extensión y de la Carrera Especialización en Didáctica de las Ciencias Sociales.
} 
DOI: 10.47694/issn.2674-7758.v2.i5.2020.226242

mandatory to dialogue from educational projects. The problem of the construction of historical knowledge and teaching to explore the change offered by multiple educational scenarios. To think about developing teaching materials together with teachers is to focus on intentionality in the world of the subject - study and teachers - and on the purposes of political-social as well as scientific. Therefore, the central focus of this article will be the analysis of research and training practices that teachers develop in the field of teaching historical knowledge.

Keyword: Teaching materials. Purposes. Teachers education.

\section{MATÉRIEL DIDACTIQUE POUR L'ENSEIGNEMENT DE L'HISTOIRE DANS LA FORMATION DES ENSEIGNANTS}

Résumé: L'élaboration de matériel didactique pour l'enseignement de l'histoire nécessite des bases théoriques et pratiques sur: l'éducation et l'utilisation de l'histoire, où et quand la faire, avec qui il est obligatoire de dialoguer à partir de projets éducatifs. Le problème de la construction de la connaissance historique et de l'enseignement pour explorer le changement offert par les multiples scénarios éducatifs. Réfléchir à l'élaboration de matériel didactique avec les enseignants, c'est se concentrer sur l'intentionnalité dans le monde de la matière - étude et enseignants - et sur les finalités politico-sociales et scientifiques. C'est pourquoi cet article sera centré sur l'analyse des pratiques de recherche et de formation que les enseignants développent dans le domaine de l'enseignement de la connaissance historique.

Mots-clé: Matériel pédagogique. Objectifs. Formation des enseignants.

\section{Presentación}

"La historia como desafio o la aventura de la curiosidad" Laura de Mello e Souza (2019)

"No es por casualidad que uno de los temas que siempre han preocupado a la filosofía, especialmente a la filosofía moderna, haya sido el de las relaciones entre sujeto y objeto, teoría y práctica, conciencia y realidad"

Paulo Freire (1974)

El dossier invita a la comunidad de profesores/as investigadores/as a reflexionar sobre la enseñanza de la historia, la formación docente y el livro didáctico. Las investigaciones que centran el análisis de los libros didáctico en el campo de la historia provienen de la historia de la educación, en tanto objeto de la cultura material escolar y de la didáctica de la historia que busca conocer cómo se elabora y circula el conocimiento histórico en el aula, en la escuela y en la sociedad. Su narrativa ofrece diferentes voces para comprender el presente y sus diferentes pasados (BECHLER; SILVA, 2019, p. 5). La complejidad de la naturaleza de ese producto cultural explica con mayor precisión el predominio como material didáctico en el proceso de enseñanza aprendizaje (BITTENCOURT, 2010, p. 71). En este artículo nos interesa abordar la producción de 
DOI: 10.47694/issn.2674-7758.v2.i5.2020.226242

materiales didácticos para la enseñanza de la historia en la formación docente en el grado y en posgrado.

Desde la teoría crítica de la enseñanza de la historia los materiales de enseñanza ayudan al alumnado a comprender la realidad social, formar su pensamiento social crítico y creativo, y tomar decisiones responsables para la participación democrática.

Los materiales de la enseñanza que se despliegan en las aulas de historia son los mediadores entre la complejidad de la realidad social y quienes quieren conocerla, son el soporte referencial del pasado que posibilita la comprensión y explicación de esa realidad social. La historiografía en los tiempos actuales aborda la dimensión histórica del conocimiento, la ampliación del archivo, la apertura a nuevos temas y protagonistas, la diversidad de lenguajes, discursos, artefactos y tecnologías del pasado y del presente.

Saber cómo se ha construido el conocimiento de la realidad y de las diversas representaciones de la misma, es un objetivo de la disciplina historia y también de la historia enseñada, poner en valor analítico critico las formas de hacer historia, entender la fuerza de las afirmaciones, ver si están sostenidas en evidencias, conocer procesos de construcción del conocimiento histórico y la provisionalidad de las conclusiones alcanzadas con la investigación, es objeto de enseñanza en las aulas, donde los materiales juegan un papel importante para lograr conocimientos, representaciones y sensibilidades.

\section{La construcción de materiales de la enseñanza en la formación docente: fundamentos y finalidades}

La didáctica de la historia se consolida como campo de estudio que atiende a los problemas de la enseñanza y el aprendizaje de determinados contenidos que están estrechamente relacionados con la disciplina de referencia. ¿Qué contenidos enseñar y qué usos sociales han de tener? ¿Están pensados para formar ciudadanías críticas y responsables? ¿Los problemas y conflictos sociales se constituyen en contenidos escolares? Las decisiones sobre cómo y con que se enseña reconoce una especificidad que deviene del estatuto epistemológico de la disciplina, de la elaboración de los contenidos, de las actividades, los lenguajes y artefactos culturales que elegimos para lograr aprendizajes en un mundo social que cambia en sus modos de información y comunicación; en la composición y relación entre las sociedades, en la correspondencia entre estados y centros 
DOI: 10.47694/issn.2674-7758.v2.i5.2020.226242

de poder económicos y políticos; que en los tiempos recientes ha profundizado las desigualdades sociales y las discriminaciones de todo tipo.

En este contexto, trabajamos la formación docente en Historia en el grado, en el posgrado y en la investigación educativa en el marco la Universidad Nacional del Comahue. En ambos lugares nos interesa pensar que la elaboración de los contenidos y los materiales de la enseñanza son creaciones, construcciones, opciones profesorales que se definen en función de las finalidades de la enseñanza.

En el estatuto epistemológico de la Historia no es válido pensar únicas opciones metodológicas, ni homogeneidades en su interior, reconocer esas peculiaridades significa asumir postura frente al problema de un conocimiento específico y su enseñanza. Reconocemos, entonces que el profesorado asume la tarea de elaborar una propuesta de enseñanza como acto creativo de articulación entre el conocimiento como producción objetiva y el conocimiento como problema del aprendizaje en un contexto determinado y en un marco axiológico /ideológico. (EDELSTEIN, 1996, p. 81; 2011, p. 145-148). Es una construcción singular, especifica y casuística en contextos singulares que se fundamenta en el estatuto epistemológico de la disciplina a enseñar, en la epistemología del sujeto que aprende y en una perspectiva axiológica en relación con la ciencia, la sociedad y la cultura. Enseñar, con un alto grado de conciencia, implica un encuentro con el conocimiento y entre sujetos.

Un punto de partida para ese encuentro: reconocer experiencias y trayectorias plurales, mirarlas en clave molecular y local, no desestimar las relaciones de poder en el campo educativo. El carácter creativo del acto de enseñar se inicia con la elaboración de la propuesta.

En ese reconocimiento de experiencias y trayectorias podemos mirar analíticamente las finalidades de la enseñanza de la historia desde la configuración del sistema educativo moderno, ya que muchas de ellas tienen una fuerte persistencia, en tanto implican modelos de sociedad vigentes.

Las finalidades direccionan la enseñanza y tienen una faceta formativa explícita, son decisiones que comprenden cuestiones sociales, morales, valoraciones, empatías, sensibilidades, tratan acerca de signibficados vitales para las y los estudiantes y su profesorado cuando apunta a una práctica epistemológica sostenida en una racionalidad de 
DOI: 10.47694/issn.2674-7758.v2.i5.2020.226242

fines. Las historias enseñadas han tenido y tienen finalidades heterogéneas legitimando diferentes concepciones de lo social, lo ético y lo pedagógico. Así pueden pensarse para: la transmisión de la cultura, la educación moral, la identidad nacional, la constitución de identidades múltiples, como herramienta en la construcción de futuro, la formación cívica política, la comprensión de la realidad social desde la complejidad, la formación del pensamiento social crítico y creativo (FUNES, 2010, p. 42-43; 2013, p. 260-262).

Nos encontramos y reencontrarnos con la historia y con sujetos que proyectan, enseñan y desean hacerlo con la utopía de lograr un acceso verdadero y concretamente igual para todos a la educación entendiéndola radical como proyecto y reformista como método para que cualquier acción local, puntual pueda ser un paso en la dirección correcta (AUGE, 2015, p. 131)

$\mathrm{Si}$ pensamos a la educación como un proyecto radical queremos sumarnos al movimiento de democratizar la democracia que mira la huella dejada por las insurrecciones del pasado accionadas por una ciudadanía reflexiva en las luchas de su propia la historia.

La democratización de la democracia es una práctica política que afronta la falta de democracia en las instituciones actuales para transformarlas radicalmente, las y los ciudadanos activos son agentes de esa transformación que se realiza en un proceso que recomienza sin cesar y cuyas formas y objetivos dependen de la realidad cambiante, que enuncia nuevos derechos fundamentales y enfrenta la regresión de otros derechos (BALIBAR, 2012, p. 108). Hay que educarse en democratizar la democracia, siendo esta una actividad que se despliega en muchos escenarios cuya convergencia no es automática, movimientos por una ciudadanía activa, una participación política para terminar con diversas exclusiones, democratizar la democracia y tener derecho a tener derechos. Premisas que en la actualidad son claves para fundamentar el porqué de la enseñanza de la historia.

Abordar la comprensión de la dinámica de las sociedades para que niñas, niños, adolescentes y jóvenes del siglo XXI comprendan temáticas y problemáticas sociales requiere del diálogo entre las disciplinas del campo de las ciencias sociales y humanas en tanto contribuye a la generación de nuevas conceptualizaciones para la comprensión de fenómenos complejos y para un aprendizaje que capacite para actuar crítica y responsablemente. 
DOI: 10.47694/issn.2674-7758.v2.i5.2020.226242

\section{Prácticas de investigación y formación en Historia: el lugar de los materiales}

Somos profesores en espacios de formación docente y que realizamos investigación educativa. Ambos lugares son escenarios de encuentros entre sujetos e historias donde se aprende, se enseña y sobre todo se enseña a enseñar (FONSECA, 2011, p. 275). En la investigación educativa que tiene por finalidad producir conocimientos en torno a la educación histórica y a la formación docente en historia, estudiamos las prácticas docentes en la formación inicial de maestros y de profesores de historia; también investigamos la formación docente en servicio atendiendo a la diversidad de experiencias formativas y laborales ${ }^{3}$.

\section{En la investigación}

En todos los casos la investigación busca recuperar las lógicas de los contextos para entramarlas con los sujetos a fin de indagar las significaciones que estos atribuyen a las diferentes situaciones, reconociendo la modalidad cualitativa, abierta, flexible y participante organizada en el estudio en casos.

Hemos indagado en contextos de fuerte crisis social, en tiempos de reformas educativas, en contextos de cultura digital y este texto lo estamos escribiendo en contexto de pandemia mundial. Buscamos entramar la lógica de cada contexto especifico con perspectivas, representaciones, expectativas, saberes de las y los sujetos en la formación inicial y en servicio.

Desde la primera investigación realizada con estudiantes que aprendían a enseñar y maestros noveles, pudimos dar cuenta de la compleja construcción de los contenidos escolares (FUNES, 2004, p. 105) que ponen de manifiesto una diversidad de formas de elaboración, todas complejas que no pueden ajustarse a tipologías y criterios universales como sugiere la didáctica tecnocrática y que en las prácticas cotidianas se desbordan por

\footnotetext{
${ }^{3}$ Proyectos de Investigación desarrollados en la Facultad de Ciencias de la Educación de la Universidad Nacional del Comahue: "De estudiantes a maestros. Aprendiendo a enseñar ciencias sociales en contextos de reforma educativa" (1999-2001); "Estudiantes y enseñanza. El caso de la geografía y la historia" (2001-2005); "Lo reciente/presente en la enseñanza de la historia" (2006-2009) "Profesores y enseñanza de la historia reciente/presente" (2010-2012) "Enseñanza y aprendizaje de las ciencias sociales y de la historia en la cultura digital" (2013-2016) "El aprendizaje escolar de las ciencias sociales en contextos de cultura digital" (2017/2020).
} 
DOI: 10.47694/issn.2674-7758.v2.i5.2020.226242

completo. $\mathrm{Y}$ en ese proceso de elaboración tienen un lugar destacado el encuentro con materiales textuales, visuales, sonoros, icónicos, donde la diversidad y pluralidad enriquece el proceso de elaboración, selección y secuenciación de los mismos.

En una pesquisa (FUNES, 2001 p.134-147), las maestras entrevistadas reconocen que los textos escolares de circulación masiva no las satisface y ello las impulsa en una búsqueda constante para encontrar, seleccionar y elaborar materiales para la enseñanza y el aprendizaje:

[...] se va tendiendo que los chicos entiendan esto de qué es la historia, quien la hace, quienes son los historiadores, a que fuentes podemos recurrir" (E. M.1:16) "trato de que tengan variada información, que vean, que las cosas pasaron por algo" (E.M.A.1:4) "Trabajo con fotocopias que armo yo...en la escuela tenemos la costumbre de pasarnos el material" (E. MA.1:5) "hacemos proyectitos, sacamos fotografías, los chicos arman la crónica. (E:MQ.2:3)

En los estudios sobre la enseñanza de la Historia Reciente/ Presente y los que indagan en la enseñanza y el aprendizaje de contenidos escolares de la Historia y las Ciencias Sociales en contexto de cultura digital desarrolladas en las ciudades de Neuquén y Río Negro nos dicen que las enseñanzas de las ciencias sociales y de la historia son múltiples y complejas. Hay una rica variedad de contextos socio- educativos, en todas las localidades trabajamos en escuelas públicas de sectores medios y marginales, con poblaciones estudiantiles heterogéneas en sus condiciones materiales y culturales: gitanos, chilenos, bolivianos, mapuches -entre otros-. Hay pluralidad de propuestas curriculares reguladas y enseñadas en el marco de proyectos institucionales. Trabajar con distintas instituciones y modalidades educativas diversifica la mirada, especializa a sujetos, a los contenidos y a los materiales de la enseñanza y nos remarca que trabajar desde la infancia potencia las posibilidades del pensamiento y de prácticas sociales críticas cuando son mediadas por proyectos de enseñanza creativos con finalidades pedagógicas fundadas que posibilitan interacciones y acciones de autonomía estudiantil utilizando una variedad de materiales escritos, orales, visuales, digitales.

Es una investigación que focaliza en la particularidad y complejidad de singularidades, que tiene como finalidad la comprensión profunda de una realidad específica: profesoras y profesores neuquinos y rionegrinos y la enseñanza de la Historia, cada caso se conforma a partir del trabajo participativo y colaborativo entre investigadores- 
DOI: 10.47694/issn.2674-7758.v2.i5.2020.226242

docentes; docentes- investigadores; estudiantes- infantes, niñas y niños, adolescentes, jóvenes y adultos- habitando un lugar de co-investigación y de formación: investigamos para formar y formamos para investigar (FUNES, JARA, SALTO, 2006, p. 276), buscamos conceptualizar desde la propia experiencia las enseñanzas y los aprendizajes que circulan en contextos específicos y sabemos que las enseñanzas que accionamos son construcciones profesorales, que se enmarcan en finalidades, que son parte de la cultura de este tiempo y que en el marco de nuestros proyectos son colectivas y colaborativas

La práctica investigativa, de formación y de enseñanza es lugar de experiencias de ruptura y/o continuidad, de pensar lo cotidiano de una manera no cotidiana, de posibilidades enriquecedoras de múltiples sentidos. La práctica es dinámica y el cambio no se realiza de manera individual sino de manera colegiada y colaborativa, en comunidades de aprendizaje profesional (HARGREAVES, 2003, p. 21) en una cultura de colaboración que se concentra en la enseñanza y el aprendizaje y en cómo mejorarlos.

Los vínculos de horizontalidad y solidaridad allanan el desafío de instalar otras prácticas y nuevos horizontes de intervención buscando avanzar hacia la superación del aislamiento del trabajo áulico por un lado, y por el otro, estableciendo un diálogo genuino, en el que prima la argumentación y la discusión, como un saber que se expone en el horizonte del otro y ante su mirada, para validar una posición o una acción, constituyendo instancias de co-formación en dos ámbitos: la enseñanza y la investigación (TARDIFF y GAUTHIER, 2005, p. 338).

El presupuesto básico es: nos interesa pensar la enseñanza en tiempos de anticipación, acción y reflexión; de quiebres y rupturas; de herencias, experiencias y trayectorias, y para hacerlo hay que construir solidariamente. En síntesis, se trata de entablar diálogos y argumentaciones desde las diferencias y trayectos formativos. Este tipo de prácticas investigativas constituyen un espacio alternativo de formación docente inicial y continua, porque evita imponer un modelo preconcebido de pensar la enseñanza de la historia y posibilita revisar finalidades que orientan acciones, discursos y el contexto en el cual el profesorado habla y actúa.

En ese espacio de co-formación interesa explorar que sucede en el aula con, desde y a partir de los materiales, sabiendo que el desarrollo tecnológico ha estado presente en las prácticas educativas desde sus comienzos con diversos artefactos y lenguajes que se han 
DOI: 10.47694/issn.2674-7758.v2.i5.2020.226242

construido y adaptado para incorporarlos en la enseñanza; la cultura de la imprenta, la visual y la digital configuran escenarios singulares y modos específicos pensados en el aula.

Si la investigación, formación y enseñanza de la historia se piensan desde el proyecto, interesa construir diagramas categoriales para analizar: el interjuego entre contenidos, materiales y actividades; el tipo de relaciones que definen al conocimiento histórico; el tiempo y el espacio como coordenadas fundamentales; la problemática asociada a los agrupamientos en el grupo clase; las decisiones administrativo institucionales; las representaciones sociales de las posiciones estudiante - docente. En fin, el aula como territorio en el que se desarrolla la formación y enseñanza es el lugar en que los sujetos sienten que se habilitan posibilidades para el despliegue de lo singular, se torna un lugar de pertenencia que se habilita placenteramente o rutinariamente.

Estamos en condiciones de afirmar que, tal como sucede en otros lados y según consta en los reportes de investigación, los materiales de enseñanza que circulan en las aulas investigadas se articulan con la cultura de la imprenta, la visual, la sonora y la digital y que los artefactos y lenguajes utilizados son variados y creativos, que se elaboran definiendo finalidades y sentidos de la enseñanza y del aprendizaje; que se articulan con contenidos construidos reconociendo la epistemología de la Historia, la epistemología de las y los sujetos que aprenden y que buscan potenciar la formación del pensamiento crítico, creativo y de la conciencia histórica en contextos determinados en su singularidad.

\section{Construimos, accionamos y analizamos}

Diversidad de perspectivas para pensar y construir contenidos: enseñamos problemas sociales, utilizamos las preguntas como estrategias privilegiadas, que en otras instancias eran antiguas preguntas para nuevos desafíos y nuevas condiciones de enseñanza; definimos núcleos y diagramas conceptuales para dar sentidos diferentes a la explicación y a la comprensión del acontecimiento o proceso. La construcción temporal de recortes problemáticos viabilizo la articulación de pasados recientes, presentes y futuros, generando aprendizajes temporales.

La pluralidad de relaciones dialécticas formas- contenidos facilitó aprendizajes cognitivos y sensibilidades, articular los problemas sociales con la realidad de niñas, niños, 
DOI: $10.47694 /$ issn.2674-7758.v2.i5.2020.226242

adolescentes y jóvenes posibilita el desarrollo de prácticas de ciudadanización y de formación política (SIEDE, 2007, p. 27).

La relación material de enseñanza-actividad se diversifica con la utilización simultánea de: fuentes y recursos multimediales de época; lectura e interpretación de textos verbales, visuales y sonoros; sensibilización frente a registros verbales, visuales y sonoros; lectura e interpretación de mapas; uso del cine de ficción y documental, videos documentales del canal Encuentro; manejo de la prensa, revistas de distinta datación (algunos coetáneos al evento y otros de ellos atravesados por la memoria del acontecimiento); utilización crítica de los cuadernos de clase; elaboración y sistematización de encuestas a estudiantes, a padres en relación con acontecimientos específicos; elaboración, ejecución e interpretación de entrevistas a informantes claves; salidas a terreno; favorecieron la multicausalidad, multidimensionalidad y multireferencialidad del contenido planteado en cada secuencia (VER CUADRO 1). 
DOI: 10.47694/issn.2674-7758.v2.i5.2020.226242

\begin{tabular}{|c|c|c|c|c|}
\hline \multicolumn{5}{|c|}{ Materiales para la Enseñanza } \\
\hline En: & Núcleos Problemáticos: & Artefacto/Dispositivo: & El profesorado los utiliza para: & El estudiantado Aprende: \\
\hline \multirow{2}{*}{$\begin{array}{l}\text { El Nivel } \\
\text { Inicial }\end{array}$} & $\begin{array}{l}\text { Rememorando fechas } \\
\text { claves: Las efemérides. }\end{array}$ & $\begin{array}{l}\text {-Videos documentales. } \\
\text {-Imágenes digitalizadas } \\
\text {-Juegos. }\end{array}$ & $\begin{array}{l}\text {-Observar e identificar modos de vida, } \\
\text { vestimentas de época. } \\
\text {-Crear escenarios lúdicos. }\end{array}$ & $\begin{array}{l}\text {-Observando quiénes y cómo se vestían. } \\
\text {-Jugando y recreando situaciones de época. } \\
\text {-Dramatizando en actos escolares sobre la } \\
\text { vida de épocas. }\end{array}$ \\
\hline & Las familias que tenemos. & $\begin{array}{l}\text {-Videos didácticos. } \\
\text {-Imágenes fotográficas sobre } \\
\text { distintas composiciones } \\
\text { familiares. }\end{array}$ & $\begin{array}{l}\text {-Observar diversidades familiares. } \\
\text {-Observar lo que hacen según su composición } \\
\text { familiar. }\end{array}$ & $\begin{array}{l}\text {-Observando imágenes que les permitan } \\
\text { identificar similitudes y diferencias. } \\
\text {-Identificando diferentes actividades que } \\
\text { realizan quienes componen una organización } \\
\text { familiar. }\end{array}$ \\
\hline \multirow{3}{*}{$\begin{array}{l}\text { El Nivel } \\
\text { Primario }\end{array}$} & $\begin{array}{r}\text { Las actividades } \\
\text { económicas de la } \\
\text { provincia en el marco de } \\
\text { los circuitos productivos } \\
\text { de la región patagónica. }\end{array}$ & $\begin{array}{l}\text {-Texto elaborado por docente } \\
\text { con información Webs. } \\
\text {-Power Points. } \\
\text {-Mapas impresos. }\end{array}$ & $\begin{array}{l}\text {-Explicar ideas claves sobre las actividades } \\
\text { económicas que se realizan. } \\
\text {-Observar relaciones entre actividades que se } \\
\text { realizan y el circuito productivo que } \\
\text { conforman. } \\
\text {-Ubicar espacialmente actividades económicas } \\
\text { concretas. }\end{array}$ & $\begin{array}{l}\text {-Observando y ubicando en mapa las } \\
\text { actividades económicas. } \\
\text {-Relacionando lecturas con imágenes y } \\
\text { conceptos presentados en Power Points sobre } \\
\text { las actividades económicas realizadas. } \\
\text {-Elaborando textos en PC sobre el } \\
\text { funcionamiento del circuito productivo. }\end{array}$ \\
\hline & $\begin{array}{r}\text { Las transformaciones } \\
\text { económicas con el modelo } \\
\text { Industrial a partir de la } \\
\text { Crisis del 29' y el Golpe } \\
\text { de Estado de } 1930 \text { en } \\
\text { Argentina. }\end{array}$ & $\begin{array}{l}\text {-Video Documental Editado. } \\
\text {-Ficha elaborada por docente } \\
\text { con base bibliográfica. } \\
\text {-Aplicación Cmap Tools. }\end{array}$ & $\begin{array}{l}\text {-Observar situaciones sobre los cambios } \\
\text { económicos de la época y protagonistas claves } \\
\text { del golpe cívico militar. } \\
\text {-Presentar y destacar conceptos claves sobre } \\
\text { Modelo Industrial y Golpe de Estado. }\end{array}$ & $\begin{array}{l}\text {-Observando imágenes audiovisuales sobre la } \\
\text { crisis del 29’ y el Golpe Cívico Militar de } \\
1930 . \\
\text {-Leyendo textos sobre causas de ambos } \\
\text { hechos históricos. } \\
\text {-Elaborando mapas conceptuales digitales en } \\
\text { formato Cmap Tools sobre la industrialización } \\
\text { a partir del Golpe Cívico Militar. }\end{array}$ \\
\hline & $\begin{array}{l}\text { Migraciones internas y } \\
\text { movimiento obrero: } \\
\text { Cambios en la clase } \\
\text { trabajadora argentina. }\end{array}$ & $\begin{array}{l}\text {-Ficha elaborada por docente } \\
\text { con base bibliográfica. } \\
\text {-Programa writer de notebook. } \\
\text {-Aplicación JClickAuthor. } \\
\text {-Audiovisual. } \\
\text { - Letra de canción "Los obreros } \\
\text { de Morón", de Jorge Marziali, } \\
\text { 1986. }\end{array}$ & $\begin{array}{l}\text {-Leer y analizar sobre la composición de la } \\
\text { clase obrera. } \\
\text {-Reconstruir la vida de los trabajadores y } \\
\text { conocer sobre la organización de la clase } \\
\text { obrera. } \\
\text {-Aportar informaciones nuevas sobre la vida } \\
\text { de los trabajadores de la época. } \\
\text {-Escuchar y ver proclama de los derechos del } \\
\text { trabajador enunciados por Perón. } \\
\text {-Organizar preguntas sobre la vida, la } \\
\text { organización y sus cambios/continuidades en } \\
\text { la clase obrera. }\end{array}$ & $\begin{array}{l}\text {-Elaborando elecciones múltiples de } 5 \\
\text { preguntas sobre la vida de los trabajadores. } \\
\text {-Intercambiándose los ordenadores que } \\
\text { utilizan236ra realizar dichas preguntas. } \\
\text { - Procesos de lectura que favorecen la } \\
\text { reconstrucción comprensiva sobre la } \\
\text { organización del movimiento obrero. } \\
\text { - Desplegando inferencias, hipótesis y } \\
\text { relaciones entre conocimientos previos y la } \\
\text { información nueva que reconstruyen del } \\
\text { movimiento obrero. -Construyendo } \\
\text { crucigramas sobre conceptos claves. }\end{array}$ \\
\hline
\end{tabular}

Revista Escritas do Tempo - v. 2, n. 5, jul-out/2020 - p. 226-242 
DOI: 10.47694/issn.2674-7758.v2.i5.2020.226242

\begin{tabular}{|c|c|c|c|c|}
\hline \multirow{4}{*}{$\begin{array}{c}\text { El Nivel } \\
\text { Medio }\end{array}$} & $\begin{array}{r}\text { El Estado teocrático en la } \\
\text { historia egipcia antigua } \\
\text { como un tipo de } \\
\text { organización estatal } \\
\text { específica. }\end{array}$ & $\begin{array}{l}\text {-Power Points } \\
\text {-Video documental } \\
\text {-Imágenes digitalizadas } \\
\text {-Textos digitalizados. }\end{array}$ & $\begin{array}{l}\text {-Organizar un guion oral y visual que permita } \\
\text { identificar características políticas y sociales } \\
\text { de los protagonistas en Egipto antiguo. } \\
\text {-Identificar situaciones, conceptos e ideas } \\
\text { claves a partir de lo observado. }\end{array}$ & \multirow{2}{*}{$\begin{array}{l}\text {-Tomando nota en sus computadores sobre } \\
\text { ideas, conceptos y argumentos sobre quiénes } \\
\text { gobiernan y cómo en el Egipto antiguo y sobre } \\
\text { las causas/consecuencias de la Conquista en } \\
1492 . \\
\text {-Leyendo y elaborando textos en grupos y } \\
\text { explicativos sobre el tema. } \\
\text {-Elaborando presentaciones en Power Points } \\
\text { para explicar la organización egipcia dentro de } \\
\text { un Estado teocrático. } \\
\text {-Elaborando audio cuentos con argumentos } \\
\text { propios sobre lo sucedido en la Conquista. } \\
\text {-Construyendo relaciones conceptuales, } \\
\text { causales y temporales en relatos coherentes y } \\
\text { con argumentaciones propias. }\end{array}$} \\
\hline & $\begin{array}{r}\text { La conquista por parte de } \\
\text { los europeos en américa } \\
\text { desde la mirada de los } \\
\text { pueblos conquistados }\end{array}$ & $\begin{array}{l}\text {-Power Points } \\
\text {-Video audio cuento } \\
\text {-Imágenes digitalizadas }\end{array}$ & $\begin{array}{l}\text {-Organizar un guion oral y visual que permita } \\
\text { argumentos sobre la conquista en } 1492 \text {. } \\
\text {-Identificar conceptos e ideas claves desde la } \\
\text { mirada de los vencidos. } \\
\text {-Observar situaciones y características } \\
\text { (disposiciones, diferencias, vestimentas, } \\
\text { armas) de los protagonistas en el hecho } \\
\text { histórico a partir de lo observado. }\end{array}$ & \\
\hline & $\begin{array}{r}\text { El radicalismo en el poder } \\
\text { a principios del siglo XX } \\
\text { significó la construcción } \\
\text { del primer régimen } \\
\text { democrático en Argentina. } \\
\text { Sin embargo frente a los } \\
\text { conflictos sociales y } \\
\text { obreros su acción fue } \\
\text { ambigua y en algunos } \\
\text { casos actuó } \\
\text { represivamente. }\end{array}$ & $\begin{array}{l}\text {-Fragmentos audio visuales. } \\
\text {-Fotografías digitalizadas. } \\
\text {-Textos digitalizados. }\end{array}$ & $\begin{array}{l}\text {-Observar tres explicaciones históricas sobre } \\
\text { el la política del radicalismo a principios de } \\
\text { siglo XX de Tulio Halperín Donghi, Félix } \\
\text { Luna y Osvaldo Bayer. } \\
\text {-Visualizar situaciones de conflicto y la } \\
\text { manera de resolverlos por parte del } \\
\text { radicalismo en el poder durante la época. } \\
\text {-Identificar ideas y argumentos y relacionarlos } \\
\text { con situaciones concretas. }\end{array}$ & $\begin{array}{l}\text {-Diferenciando registros narrativo- } \\
\text { explicativos orales de expertos en el campo. } \\
\text {-Valorando críticamente las evidencias y las } \\
\text { fuentes de información que ofrecen los } \\
\text { historiadores; } \\
\text {-Observando e interrogando fuentes visuales } \\
\text { para obtener información de ellas; } \\
\text {-Repreguntando y buscando/ampliando } \\
\text { información en otros medios (páginas Webs); } \\
\text {-Leyendo narrativas y escribiendo significados } \\
\text { construidos en relación al proceso histórico } \\
\text { estudiado. }\end{array}$ \\
\hline & $\begin{array}{r}\text { “A partir de } 1943 \text { emerge en } \\
\text { la escena política argentina } \\
\text { una figura: Juan Domingo } \\
\text { Perón. La construcción de su } \\
\text { régimen es considerando uno } \\
\text { de los más importantes del } \\
\text { siglo XX y constituirá una } \\
\text { nueva fuerza política que } \\
\text { perdurará hasta la } \\
\text { actualidad. ¿Por qué la } \\
\text { Argentina sigue siendo } \\
\text { mayoritariamente } \\
\text { peronista?” }\end{array}$ & $\begin{array}{l}\text {-Redes conceptuales. } \\
\text {-Cuestionarios. } \\
\text {-Videos documentales y } \\
\text { testimoniales. } \\
\text {-Fragmentos de textos de } \\
\text { autores específicos. } \\
\text {-Imágenes fotográficas. }\end{array}$ & $\begin{array}{l}\text {-Observar la relación entre el peronismo, la } \\
\text { clase obrera argentina y los sindicatos. } \\
\text {-Identificar características de la relación a } \\
\text { partir de explicaciones argumentadas de } \\
\text { especialistas: Novaro, Tcach, Belini. } \\
\text { - Elaborar relaciones con estudiantes a partir } \\
\text { del aporte de documentales sobre situaciones } \\
\text { de conflicto y de la reconstrucción del } \\
\text { testimonio de los propios protagonistas de } \\
\text { cada época (Rucchi, Tosco, entre otros). }\end{array}$ & $\begin{array}{l}\text {-Construyendo un marco explicativo propio y } \\
\text { argumentado sobre la relación Peronismo, } \\
\text { clase obrera y sindicatos. } \\
\text {-Observa37lo documentales y testimonios } \\
\text { sobre situaciones de conflicto y testimonios de } \\
\text { sindicalistas. } \\
\text {-Organizando información en cuadros } \\
\text { comparativos. } \\
\text {-Respondiendo cuestionarios con preguntas } \\
\text { guías sobre lo observado. }\end{array}$ \\
\hline
\end{tabular}

Revista Escritas do Tempo - v. 2, n. 5, jul-out/2020 - p. 226-242 
DOI: 10.47694/issn.2674-7758.v2.i5.2020.226242

En el CUADRO 1 solo destacamos algunos casos de la diversidad de experiencias en las que hemos colaborado con el profesorado de distintos niveles educativo de nuestra región. Los cuales, en términos generales, nos permiten dar cuenta de la variedad de dispositivos/artefactos que en sus diferentes formatos el profesorado utiliza en la clase. Que la mediatización, cuando se pone en juego, de las redes sociales también produce una extensión de la clase al espacio virtual y amplían las posibilidades de búsqueda para la selección de materiales, al mismo tiempo que les resulta necesario utilizar criterios de selección fiables al navegar en la web.

La totalidad del estudiantado al que acompañamos en estas experiencias posee computadoras y teléfonos móviles, lo que les permite conectarse a la red de redes y utilizar los artefactos desde un saber práctico. Hacen uso de las redes sociales, materiales digitalizados, Power Points, buscan información, escriben trabajos, miran películas, editan fotografías, escuchan música. Indagan en sitios web: Google Académico, Clacso, Redalyc, Canal Encuentro, Educar.

En varios casos la utilización de la computadora y la proyección de películas e imágenes desde el cañón, contribuyen de forma positiva en el desarrollo y explicación de los contenidos en las clases. La posibilidad de "confrontar materiales" digitales y textos tradicionales fomenta el debate para que los/as estudiantes asuman una postura crítica respecto de los mismos. El video, aporta la posibilidad de ver material documental como fuente de época y promueve un aprendizaje visual que mejora la internalización de los contenidos. E incluso en edades tempranas favorece las estrategias de comparación con viajes interactivos en espacios y tiempos distintos, facilitando y enriqueciendo el desarrollo de capacidades y miradas diversas. Así, el predominio de la imagen, la velocidad, los mensajes y discursos fugaces cobra presencia en el mundo infantil.

La reconstrucción crítica de lo actuado en las múltiples clases, los análisis didácticos (EDELSTEIN, 2011, p. 34) nos indican que los materiales construidos se convirtieron en reveladores de significados y provocadores de transformaciones del proceso didáctico facilitando y potenciando enseñanzas y aprendizajes de historias. Profesoras y profesores tienen formación y experiencias muy potentes, conocen y utilizan diversos artefactos y lenguajes en la mayoría de las escuelas y en las aulas circulan diversos materiales que el profesorado elabora con diferentes modalidades, con distintos resultados 
DOI: 10.47694/issn.2674-7758.v2.i5.2020.226242

por las condiciones de recepción y apropiación, los alcances y límites, los sentidos y usos, pero todas las experiencias posibilitan aprendizajes diferentes.

\section{En la formación docente}

Decíamos en páginas anteriores que investigamos para la formación, ella nos permite tener conocimientos validados de lo que sucede en las escuelas y en las aulas en las que realizamos esa práctica y allí visualizamos que la elaboración de materiales de enseñanza no siempre tiene un lugar en la formación inicial y en la posgraduación.

En nuestra universidad se desarrolla una Especialización en Didáctica de las Ciencias Sociales con Mención en Historia, Geografía y Educación Ciudadana, esa carrera tiene un espacio curricular denominado Elaboración de materiales para la enseñanza de las Ciencias Sociales, tiene la modalidad de Taller y se desarrolla en $40 \mathrm{hs} / 3$ créditos. Sus contenidos mínimos son:

La elección y elaboración de materiales en relación con las perspectivas de la enseñanza del conocimiento social.

Los rasgos culturales de la sociedad de la información. Nuevos escenarios educativos. Lógicas de producción y criterios de evaluación de materiales educativos para una enseñanza critica de las Ciencias Sociales.

Cómo y con qué enseñar a pensar socialmente la realidad.

Ord. 0639/12 p.10. CS. UNCo

Este Taller es obligatorio y en general es valorado positivamente porque es un espacio que posibilita reflexionar sobre fundamentos y finalidades de la selección y elaboración como así también analizar cómo se juegan las perspectivas y tradiciones de la enseñanza en los mismos. También es un lugar para realizar propuestas de enseñanza concretas o para revisar analíticamente las que están practicando. Las producciones profesorales son creativas y potentes para buenas enseñanzas.

En la formación docente del profesorado en Historia de la misma universidad y en el marco de la asignatura Práctica Docente también realizamos las Jornadas de Prácticas Docentes de la Enseñanza de la Historia; un dispositivo innovador en la formación inicial en el que las y los estudiantes comparten experiencias y polifonías de sentidos y saberes (SALTO, 2017, p. 39). En su $8^{\circ}$ edición, las Jornadas 2019 versaron sobre los "Materiales en la Enseñanza y el Aprendizaje de la Historia y las Ciencias Sociales" permitiendo focalizar la mirada en la multiplicidad de posibilidades abiertas y atendidas desde la 
DOI: 10.47694/issn.2674-7758.v2.i5.2020.226242

formación inicial del profesorado. La presentación de materiales vinculados al juego, a las imágenes pictográficas, al texto escolar de elaboración propia, a los dispositivos multidigitales, al uso de fuentes escritas y testimoniales, de redes sociales y de ficción, todos ellos destinados a la enseñanza y al aprendizaje escolar dieron cuenta de esta apertura. Cuya polifonía abierta desde la propia voz de practicantes del profesorado sobre su propia experiencia también se abrió a la de aquellos que fueron estudiantes de practicantes (jóvenes de escuelas secundarias), entablando un diálogo enriquecedor en torno a una propuesta de formación que permite visibilizar, promover y favorecer alternativas concretas para un pensamiento didáctico autónomo orientado a la enseñanza de contenidos históricos y sociales. Propuesta que en los actuales contextos de pandemia mundial se encuentra en curso de asumir los renovados desafíos que se nos presentan en el marco de la formación inicial y continua del profesorado.

\section{Finalizando}

En los fundamentos y finalidades sostuvimos que pensamos a la educación como un proyecto radical y queremos sumarnos al movimiento de democratizar la democracia, que en las escuelas y las aulas de historia tienen un lugar central. Los contenidos y materiales didácticos relevantes en el ámbito académico y en la educación elemental están instalados desde lo vivencial, emotivo, ideológico, y cuando los enseñamos cobran importancia las perspectivas desde las cual nos posicionamos (TEJERINA, CARRIZO, 2016, p. 46). Son contenidos y materiales controversiales y el profesorado despliega diversas estrategias para la lectura analítica del proceso o suceso. Reconocer la función política de la didáctica de la historia, permite saber que enseñar a pensar lo social nos introduce en la historia como desafío o como aventura de la curiosidad (MELLO e SOUZA, 2019, p. 270) poniendo en diálogo a los sujetos que aprenden, los que enseñan y la historia como vinculo cultural y de sentido en el trabajo cotidiano de la clase. Una didáctica desde la perspectiva socio-cultural involucra e interrelaciona docencia, saberes circulantes y vivencias estudiantiles en el aula (BAZAN, 2019, p. 200). Las historias recientes y del presente habilitan una educación temporal, cognitiva y emocional que posibilitaría tomar posición frente a cuestiones de la sociedad. El acceso al mundo de la ciencia y del arte, así como a las políticas públicas educacionales y culturales son derechos de los ciudadanos; por lo tanto, son elementos 
DOI: 10.47694/issn.2674-7758.v2.i5.2020.226242

relevantes para la formación de profesores en Historia (FONSECA, MARTINS, 2019 p. 213). Para que la educación se constituya en un proyecto radical para democratizar esta democracia del presente, las historias proyectadas, enseñadas y deseadas requieren articular en el desarrollo cultural e intelectual del estudiantado a la formación ética y estética y en ella los materiales de la enseñanza cobran un lugar destacado.

\section{Bibliografía}

AUGÉ, Marc. ¿Qué paso con la confianza en el futuro? Buenos Aires: SXXI editores, 2015.

BALIBAR, Étienne. Ciudadanía. Buenos Aires: Adriana Hidalgo Editora: 2012.

BAZAN, Sonia. Historias urgentes para ciudadanías mestizas. FUNES, Alicia G., JARA, Miguel Investigación y prácticas en Didáctica de las Ciencias Sociales. Tramas y vínculos. Neuquén: Educo, 2019.

BECHLER, Rosiani Riveiro; SILVA, Cristiani Bereta da. Livros didáticos como textos de memória: notas sobre narrativas da imigração alemã em livros didáticos de história regionais. História da Educação (Online) v. 23: e81563. 2019 DOI: http://dx.doi.org/10.1590/2236-3459/81563

BITTENCOURT, Circe. Livros didácticos entre textos e imagens. In: BITTENCOURT, Circe (org.) O saber histórico na sala de aula. Sao Pablo: Contexto, 2010.

EDELSTEIN, Gloria. Formar y formarse en enseñanza Buenos Aires: Paidós: 2011.

. Un capitulo pendiente: el método en el debate didáctico contemporáneo. AAVV. Corrientes didácticas contemporáneas. Buenos Aires: Paidós, 1996.

FONSECA, Selva G. Aprender a ensinar história en em espacos intersticiais: reflexoes sobre o papel formativo do "Perspectivas...". In: FONSECA, Selva G.; GATTI JR, Decio (org) Perspectivas do ensino de História: ensino, cidadania e conciencia histórica. Uberlándia: Edufu, 2011.

FONSECA, Selva G.; MARTINS, María. Formarse profesor de Historia: ciudadanía y arte en las tramas curriculares. FUNES, Alicia G., JARA, Miguel Investigación y prácticas en Didáctica de las Ciencias Sociales. Tramas y vínculos. Neuquén: Educo, 2019.

FREIRE, Paulo. Concientización. Buenos Aires: Ediciones Búsqueda: 1974.

FUNES, Alicia Graciela. Historia, docentes e instituciones: un dialogo difícil en contextos de reforma educativa. Tesis (Maestría en Didáctica), Universidad Buenos Aires, Buenos Aires, 2001. 
DOI: 10.47694/issn.2674-7758.v2.i5.2020.226242

FUNES, Alicia Graciela. Historias enseñadas recientes. Utopías y prácticas. Neuquén: Educo: 2013.

Historias enseñadas: futuros posibles Revista Novedades educativas. n. 235. p. 4246. Argentina, Julio. 2010. Las ciencias sociales el gran desafío. Neuquén: Educo: 2004.

HARGREAVES, Andy. Enseñar en la sociedad del conocimiento (La educación en la era de la inventiva). Barcelona: Octaedro:2003

JARA, Miguel; SALTO, Víctor; FUNES, Alicia Graciela. La historia reciente. Investigar para enseñar y formar en las Ciencias Sociales GOMEZ RODRIGUEZ, Antonio; NUÑEZ GALIANO, M. Pilar. Formar para investigar, investigar para formar en la Didáctica de las Ciencias Sociales. Málaga: AUPDCS, 2006.

REIS, Marcus Vinicius; ASSIS, Angelo Adriano Faria de. Laura de Mello e Souza: História como desafio ou a aventura da curiosidade. Escritas Do Tempo, 1(3), 270-278. 2020 Recuperado de https://periodicos.unifesspa.edu.br/index.php/escritasdotempo/article/view/1209

SALTO, Víctor. Tensiones y desafíos de la práctica docente del profesorado en Historia. In: Prácticas docentes de la Enseñanza de la Historia: narrativas y experiencias. Cipolletti: Universidad Nacional del Comahue. Facultad de Ciencias de la Educación, 2017.

SIEDE, Isabelino. La función política de la escuela en busca de un espacio. In: SCHUJMAN, Gustavo; SIEDE, Isabelino. Ciudadanía para armar. Aportes para la formación ética y política. Buenos Aires: Aique, 2007.

TARDIFF, Maurice y GAUTHIER, Clerdmont. El maestro como "actor racional". In: PAQUAY, Leopol; ALTET, Marguerite; PERRENOUD, Philippe. (coords) La formación profesional del maestro. Estrategias y competencias. México: Fondo de Cultura Económica,2005

TEJERINA, M. Elina; CARRIZO, Karina. Atravesamientos, imágenes y sentidos en la enseñanza del peronismo. Reseñas de Enseñanza de la Historia. Córdoba: APEHUN, 2016.

Artigo recebido em 19 de junho de 2020. Aprovado em 29 de agosto de 2020. 